the presence of an electron space charge, and we have consequently very different and variable impedances throughout the motion. The existence of a fluctuating space charge combined with one produced by positive ions (produced in the electrolysis) could give fluctuating space charge clouds when recombination takes place in the rather specialized geometrical structures involved. These effects would be more pronounced as the temperature increased to the point at which ionic conduction became important. One can visualize a fluctuating effect of this kind arising through lack of equilibrium in the intervals between observations : (of the order of a few seconds) thus involving a decay, with a time constant of the same order of magnitude : this picture is consistent with results obtained under pulsed conditions ( $\mu$ sec. pulses) by ourselves and also by other workers in this field.

We hope to publish these results in full at a later stage of the work.

Margaret Chisholm L. JACOB

Department of Natural Philosophy, Royal College of Science and Technology, Glasgow, C.1.

Aug. 11 .

Radar Echoing Area Polar Diagrams of Birds

As part of an investigation into the sources of unidentified radar point echoes, or 'angels' ${ }^{-3}$, we have been measuring the echoing area polar diagrams ${ }^{4}$ of birds, using a high-resolution X-band radar. This radar, which is horizontally polarized, is capable of measuring equivalent echoing areas as low as $2 \times 10^{-6} \mathrm{sq}$. metre with an accuracy better than $\pm 1 \mathrm{db}$. and of detecting even smaller radar targets. Each bird in flying position, but with wings closed and legs retracted, was fixed to a nylon cord. The nylon cord was held vertically between ground and an aerial line suspended between two towers. Typical azimuth polar diagrams for three birds are shown in Fig. 1. Each pattern was made with the aerial of the radar fixed in elevation and bearing, while the bird was rotated in bearing about a point at the centre of its body. The rate of rotation of the specimen and the time constant of the equipment provide a smoothing factor over approximately $10^{\circ}$ in azimuth. This smoothing factor provides satisfactory 'averaging' and removes the fine lobe structure. The spacing between radar and bird was chosen to give an even illumination of the rotating bird. The birds were placed at heights which coincided with the radar aerial elevation angle of approximately $18^{\circ}$, an arrangement which ensured a low side-lobe background and consequently optimum radar sensitivity. The bird echoing areas were evaluated by comparison with standard metal spheres.

The echoing area polar diagrams, taken in azimuth, for a domestic pigeon, a starling (Sturnus vulgaris) and a house sparrow (Passer domesticus) are shown in Fig. 1. Only half the diagram is shown; the other portion covering bird aspects from $180^{\circ}$ to $360^{\circ}$ in azimuth, is a mirror image of the diagram in Fig. 1. Maximum echoing areas occur between $65^{\circ}$ and $115^{\circ}$
Table 1. Maximcm and Mrimum Echoing Areas

$\begin{array}{lccc}\text { Specimen } & \begin{array}{c}\text { Aspect } \\ \text { Broadside } \\ (\mathrm{sq} . \mathrm{m} .)\end{array} & \begin{array}{c}\text { Head } \\ (\mathrm{sq} . \mathrm{m} .)\end{array} & \begin{array}{c}\text { Tail } \\ (\mathrm{sq} . \mathrm{m} .)\end{array} \\ \text { Pigeon } & 1.0 \times 10^{-2} & 1.1 \times 10^{-4} & 1.0 \times 10^{-4} \\ \text { Starling } & 2.5 \times 10^{-3} & 1.8 \times 10^{-4} & 1.3 \times 10^{-4} \\ \text { House sparrow } & 7.0 \times 10^{-4} & 2.5 \times 10^{-5} & 1.8 \times 10^{-5}\end{array}$

in bearing, that is, when the birds are broadside-on to the radar. The minimum areas coincide with tail-on and head-on positions of the bird, with respect 10 the radar beam. Principal maximum and minimum echoing areas for the three birds are given in Table 1 .

Measurements were then made on the effect of the feathers and the contribution of the wings to the echoing area. A pigeon was plucked, the feathers and body being measured separately. The echoing area of the feathers, packed into a thin polythene bag, was approximately $5 \times 10^{-5}$ sq. metre when viewed from the direction presenting maximum area to the radar. The plucked bird was also measured and it produced a similar diagram to that shown for the bird in plumage. A rook (Corvus frugilegus) was measured in the broadside position and gave a peak echoing area of $2.5 \times 10^{-2}$ sq. metre. The bird, with outstretched wings, was then fixed with its body parallel to the nylon cord and peak echoing areas of back and belly views were measured. These outspread wing views of the bird were similar in peak echoing area, and differed from the broadside measurement by less than 5 per cent.

We gratefully acknowledge the help of our colleagues at the Royal Aircraft and Royal Radar Establishments and to Mr. I. M. Hunter, of the Royal Aircraft Establishment who proposed the experimental measuring system.

Royal Aircraft Establishment,

$$
\text { J. EDwards }
$$

Farnborough.

Royal Radar Establishment,

\section{E. W. HOVGHTON} Great Malvern.

Harper, W. G., Nature, 180, 847 (1957)

Sutter, E., Ornith-Beob.. 54, 70 (1957).

Soc., B, 149, $503(1958)$.

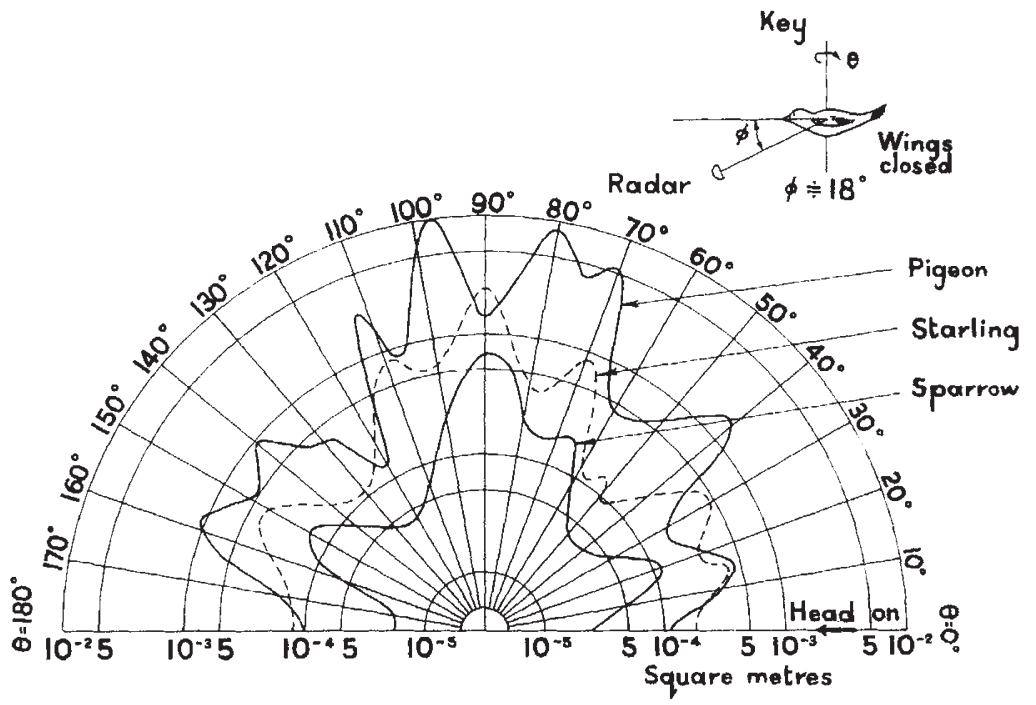

Fig. 1. Echoing area polar diagrams in azimuth, at $X$-band. 